\title{
Community Based Assessment of Reproductive Health and Related Problems of Communities at Quiha Town, Keble 02, Mekelle Zone, North Ethiopia
}

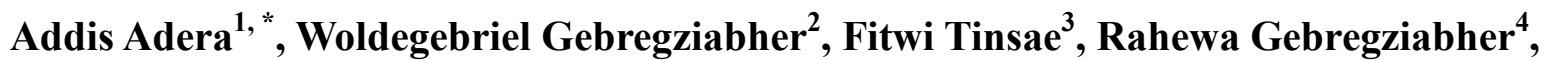 \\ Rosa Gebrekidan ${ }^{4}$, Ruta Solomon $^{4}$, Sara Abrha ${ }^{4}$, Seida Ashmael $^{4}$, Serke Reta $^{4}$, \\ Senait Gebregziabher ${ }^{4}$, Senait kassie ${ }^{4}$, Tedros Fissehaye ${ }^{4}$, Tigist Shimel ${ }^{4}$ \\ ${ }^{1}$ Department of Nursing, Faculty of Health Sciences, Woldia University, Woldia, North Wollo, Amhara Region, Ethiopia \\ ${ }^{2}$ Department of Midwifery, Faculty of Health Science, Adigrat University, Tigray, Ethiopia \\ ${ }^{3}$ Department of Nursing, Dr.Tewelde Legesse Health Science College, Mekelle, Tigray, Ethiopia \\ ${ }^{4}$ Department of Nursing, Sheba University, Mekelle, Tigray, Ethiopia
}

Email address:

addisaderagebru@gmail.com (A. Adera)

\section{To cite this article:}

Addis Adera, Woldegebriel Gebregziabher, Fitwi Tinsae, Rahewa Gebregziabher, Rosa Gebrekidan, Ruta Solomon, Sara Abrha, Seida Ashmael, Serke Reta, Senait Gebregziabher, Senait kassie, Tedros Fissehaye, Tigist Shimel. Community Based Assessment of Reproductive Health and Related Problems of Communities at Quiha Town, Keble 02, Mekelle Zone, North Ethiopia. Science Journal of Public Health. Vol. 3, No. 4, 2015, pp. 572-582. doi: 10.11648/j.sjph.20150304.27

\begin{abstract}
Background: Pregnancy at age interval of 15-19 years old and some of the community exercise $<15$ years old have shortage of health education for them about the harmfulness of the early marriage in a community Because reproductive health is such an important component of general health it is a prerequisite for social, economic and human Development. Most women have accepted traditional practice without any question, especially on subjecting themselves and their daughters to genital mutilation, early marriage, milk teeth extraction and domestic abuse with increased government efforts to expand family services. Hence, it is important to understand the exposure of communities to sexual and reproductive health knowledge attitude, and skill at different kebeles including each household. Objectives: The main objective of this study is to assess the major reproductive health status and communities problem in study area. Method: A cross sectional survey using selfadministrated questionnaire was conducted in Keble, 02 Quha town, Mekelle zone from June, 2010 up to July, 2010. Data was collected by protested questionnaire though interview. After coding and cleaning, data was entered and analyzed using tally sheet and scientific calculator. The analyzed data was presented using tables, graphs and Charts. Result:- A total of 360 respondents on the study; the majority (47.5\%) being in the age of $31-45$, and $108(30 \%)$ were male and $252(70 \%)$ were female . of the total 75(20.8\%) male were married but $110(30 \%)$ female were divorced by marital status. out of the total 93 $(37.6 \%)$ respondents had knowledge on family planning, but also $79(81.4 \%)$ were use inject able method currently. Regarding using latrine among the communities, the majority of 126 (34\%) participants were use pit latrine In addition 255 (77\%) participants were utilized tape water and 126(66.83\%) had also economical problem.
\end{abstract}

Keywords: Contraceptive, Knowledge/Awareness, Infant Mortality Rate, Attitude/Belief

\section{Introduction}

Reproductive health, or sexual health/hygiene, addresses the reproductive processes, functions and system at all stages of life (1). Reproductive health implies that people are able to have a responsible, satisfying and safer sex life and that they have the capability to reproduce and the freedom to decide if, when and how often to do so(2). Investing in reproductive health is an upstream investment. Quite simply, a woman's good health before pregnancy will contribute to a healthy pregnancy; a healthy pregnancy will contribute to a healthy birth outcome; and a healthy birth outcome, along with preparation for parenthood, will contribute to healthy children and families $(3,4)$ Poor birth outcomes will contribute to poor short- and long-term growth and development outcomes for infants and children. These negative outcomes may have lifelong impacts and may result in increased cost 
and strain to families and to society overall. Poor birth outcomes can levy substantial costs to health care (e.g., more frequent and longer hospital stays, primary care) education, the justice system, non-profit organizations and all levels of government (5).Community participation is a proven approach to addressing health care issues and has been long utilized in HIV prevention in the United States and in development internationally, in projects varying from sanitation to child survival, clean water, and health infrastructure. However, the quality of participation varies from project to project. Moreover, in spite of the failure of many health programs designed without the participation of target communities, some professionals continue to question the value of community members' participating in program design, implementation, and evaluation(6). One interpretation of this implies that men and women ought to be informed of and to have access to safe, effective, affordable and acceptable methods of birth control; also access to appropriate health care services of sexual, reproductive medicine and implementation of health education programs to stress the importance of women to go safely through pregnancy and childbirth could provide couples with the best chance of having a healthy infant. India is home to one-sixth of the world's population, and to $30 \%$ of youth aged 10 24.There are more than 211 million 15-24-year-olds in India, and they account for $48 \%$ of the country's fertility. The total fertility rate in 2005-2006 was 2.7 children per woman, but there was much variation among states, from 2.0 (below replacement level) in Kerala to 4.0 in Bihar and 4.6 in Meghalaya (8, 9). Early marriage and childbearing are common in India: The median age at marriage for females is 16.7 , well below the legal age of 18 , and $28 \%$ of women aged 20-49 gave birth before age 18. ${ }^{1}$ Contraceptive use by mothers younger than 25 is negligible, resulting in short inter pregnancy intervals. Women usually achieve their desired fertility of 2-3 children by age 25 and then adopt a permanent method $(10,11)$. Sexuality and reproduction are among the most fundamental aspects of life. Yet they often receive little attention in public policy discussions because of cultural and political sensitivities, particularly in the Middle East and North Africa (MENA) region $(12,13)$. The present demographic trend suggests that that Ethiopia will have bear the burden of unprecedented rapid population growth beyond its resources in the year ahead unless effective measures are taken by the government to moderate demographic trends of the countryICPD(1994).The demographic factors responsible for the demographic growth rate are continuous high rate and slowly declining mortality rate, available data indicate that the total fertility rate increased from 5.8 children (women in 1970 to 6.1 children). Women at present although the figure varies from region to region (14). Studies in the number of countries have shown that whenever fertility is high maternal and infant child mortality rate is high. The family planning use is also noted to be poor. The current estimation of CPR is $9.8 \%$ which is very low as compared to many countries Antenatal and post natal care is also scoring in the light of consequences (15) other component of reproductive health such as treatment and prevention of unsafe abortion, safe delivery, maternal nutrition and sexually transmitted disease including HIV/AIDS one under series condition that highly influences the reproductive health status of Ethiopian women $(15,16,17,18)$. Most women have accepted tradition without question, subjecting themselves and their daughters to genital mutilation, early marriage, milk teeth extraction and domestic abuse. With increased government efforts to expand family services, more women will be reached, in the process saving lines and giving women and their families greater hope but with political will there must be approved the health infrastructure and contribution system. Although family planning tools are available in Ethiopia, access to them has major hindrance for the majority of the women, planned parenthood state Quite often we adopt some concept of it, Nevertheless when it comes to knowing what it actually mean, there is remain wide discrepancy between what is know and what is actually is. This has serious implication in solving problem pertaining to it and creation of relevant awareness about reproductive health status and problem of the community are considered as an important areas of health service focus, there is steal the problem in understanding the meaning and component of reproductive health from wide experiences. The problem is also important to nursing because Nurses are priority takers of women in reproductive age during prenatal care, labor and delivery, postnatal care and in guidance as well as in counseling of women at any settings. Nurses are playing prominent role In RH thus working in this area in the country will provide we nurses a clear picture of it. In addition, gender in equality in health is also true of the social dimension. Gender in equality is manifested in the $3^{\text {rd }}$ world societies. Therefore, strategies eradicated such as inequalities including in the area of health must focus an improvement of the status of women. The Ethiopian government is committed to address women right in several and reproductive health in particular. This can be noted in various polices. There are also basic areas of emphasis-identified order to enhance solution to recognized problem. Those include operational zing the integration and management of RH (intervention, Improving quality care of family planning method.

According to the study done during 2007 G.C on the vital static's and socio-demographic characteristics the total population of the world was 6,625 million under vital static's indicator the result calculated were CBR was 21 per 1000, CDR was 9per 1000,IMR was 52 per 1000 and the total fertility rate was 2.7 per women having $(16,17,18)$.The Africa population as indicated in this study was 944 million was this vital static's indicator having a result indicated by rate including CBR which was 38 per 1000 , CDR 4per, RNI which was 2.4 per 1000 , IMR which was 86 per 1000 TFR which was 5 per women and life expectancy at birth for females is 54 years while for males is 52 years(10). According to the survey done by FDRE, MOH on health and health related condition indicated the total population of our country was $77,127,000$ in 1999 E.C of which $38,644,000$ where males and 38,483.000 where females having a sex 
ratio 100.4 and dependency ratio according 843 from the population percentage $3.1 \%$ were $23.9 \%$ an over whelming majority of birth in the 5 years before the survey were delivered at home (94\%) 5\% birth were delivered in public facility (19). According to DHS 2005 presents ever use of contraceptive among three groups of women currently married women, un married women, and sexually active women by current age the data indicated $18 \%$ of all women and $24 \%$ currently married women have used a method of some time (9). Women are much more likely to have used a modern method than traditional method. Inject able have been the most commonly used modern method. A rhythmic has been the most widely employed traditional method.(14). The Contraceptive prevalence rate for married Ethiopian women are used currently a method of family planning is $15 \%$ almost all those uses are using modern method.

The most widely used method is inject able which accounts for $3 \%$ As expected contraceptive prevalence is more than four times higher in urban than rural $(47 \%$ and $11 \%(9)$.Current use of contraception increased in five folds from $16 \%$ among women with no education to $53 \%$ among those with secondary and higher level of education (DHS 2005)(14). According to the study conducted by ministry of the health and health related indicators in 1999E.C. The national population of according 77,127,000 and the Oromia population $23,304,000$ according to the report of this study the total number of live births of the nation is $2,753,434$, of which 1,0181, 439 of the total level live births are Oromia region (15). As this study revealed that from the total deliveries of the nation $16.4 \%$ are attended by skilled health personnel and from the total deliveries in the Oromia region $12.1 \%$ are attended by skilled health personnel on the other hand from the total deliveries of the nation the proportion of the deliveries attended by TTBA are 7.3 and from the region Oromia 10.3 are attended by TTBA (15). As it is indicated in the report of this study the ANC coverage of the nation is $52 \%$ and the region Oromia is $39.7 \%$ the proportion of contraceptive users nationally. As indicated in this study (done in 1999 E.C) is $29 \%$ users pills $38.5 \%$ users inject able and $31.2 \%$ uses condom. There is no report on the percentage of contraceptive users in the 1999 E.C) study done by MOH on health and health related indicators. But a according to the study conducted in 1998 E.C on health and health related indicators the percentage of contraceptive uses in Oromia region $26.27 \%$ users pills, $50.2 \%$ uses inject able and $18.6 \%$ users condom as well as according to DHS Ethiopia women's married at age interval between 15-19 account for 18\% (16). According to the WHO definition on FGM constitutes are the procedures which involves partial or total removal of the external female genitalia or other injury to the female genital organs whether for cultural or any other non therapeutic reasons (17). Estimates of the Number of female of all age's in Africa who have been circumcised range from 80 million in 1982 to 100 million in 1980 , the national committee on traditional practice In Ethiopia (NCTPE) reported that infibulations is common among women in Hararge and Somalia region, exclusion among Gurage clitrodectomy is common among Amhara and Tigray speaking Muslims called jeberti NCTP reported that the practice is lower among younger women and urban-rural residents (17). The main aim was to of this study is to assess the major reproductive health status and communities problem in study area.

\section{Method and Materials}

\subsection{Study Area and Period}

The study was conducted in Keble 02, Quiha woreda, Mekelle Zone, Tigray, Ethiopia.. . Ethiopia is one of the developing countries found in east Africa. Its total population is 80 million. From the total population there are nine regions and two special city administrations. Those regions have their own languages, religion and ethnic groups. Tigray is one of the nine regions bordered by Sudan to the west, the afar region to the East and Amhara region to the South. Based on the 2007 census con ducted by central statically agency (CSA), the Tigray region has an estimated total population of 4,314,456 of whom $2,124,853$ are men and $2,189,603$ women, Urban inhabitants number 842,723 or $19.535 \%$ of the population. From the entire region 985,654 households were counted, which results in an average for the region of 4.4 persons to a house hold with urban households having on an average 3.4 and rural households 4.6 people. Tigray was formerly known as region one. Its capital is Mekelle. Mekelle is the capital city of Tigray region, which is situated about $776 \mathrm{~km}$ North of Addis Ababa. Based on the study conducted in 2005 has an estimated total population of $4.334,996$ and area of 50, 078, $64 \mathrm{~km}^{2}$. Under the Mekelle administration Quiha Town is the major one. Quiha town is located in the Northern Ethiopia. The name comes from the local word for willows, which are abundant in the area, Located in the southern Zone of Tigray region, it lies $10 \mathrm{Kms}$ South of Mekelle Straddling the high way that leads to Addis Ababa. It has altitude and Longitude of $13^{\circ} 29 \mathrm{~N} 39^{\circ} 38^{1} \mathrm{E}$ with an elevation of 2247 meters above sea level. Quiha town has bounded in three directions, by two Tabia Woreda Enderta in North shibta, south Mytsedo and shibta, East Mytsedo, and west Hadnet Quiha has three kebeles and seven ketemas. Based on figures from the central tactical agency in 2005, Quha has an estimated total population of 12,543, of whom 5,644 were males and 6,899 were females. From women found in reproductive age group (15-49) according to the 1994 census report women's in reproductive age 3384 , children $<5$ years 2504 , children aged $<1$ years 601 are found. Finally, the health service of Quiha town has two hospitals, one health centers and three private pharmacists. Quiha Health Center currently gives seventeen services, from services treating; giving cares health promotion and health prevention are the main one. Ethiopia is the most populous country in Africa with population of about77, 127.00(PRDH 1999).It has been estimated that at the current annual growth rate of $3-9 \%$ the population of Ethiopia will approach 140 million by the 2020(2).The study was conducted in kebelel o2, randomly selected participants from June 2010 9upto 
July , 2010 in the city.

\subsection{Study Design}

Across sectional community survey was employed.

\subsection{Study Population}

The sampled participants who are living in Keble 02, Quhia, Mekelle Zone prior to the study. The source of the population was all reproductive age group women in Quiha Town Keble 02 and selected samples. The study population was all reproductive women who have one or more child who are selected by systematic sampling method from the total house hold of Kebele, 02 and all selected households.

\subsection{Sample Size}

The sample size was determined by using a single population proportion formula considering the following assumptions: proportion of participants in community services and who are at reproductive age groups $50 \%$ $(\mathrm{p}=0.5 \%)$. level of significance to be $5 \%(\alpha=0.05), \mathrm{Z} \alpha / 2=1.96$ margin of error to be $5 \%(\mathrm{~d}=0.05)$ and design effect $=2$. By adding $10 \%$ non-response rate, the final sample size was 360 .

\subsection{Sampling Techniques}

Formerly the total sample size was distributed to each kushet of the Keble proportionally. Then based on the registration of the class the study unit was selected using systematic random sampling techniques. The interval was done based on the numbering and according to their location and the first house was selected by lottery method and others are selected by every three houses based on systematic methods until the total sample of 360 has been drown.

\subsection{Instruments and Measurements}

Pretested and structured questionnaire was used. Translation of instruments is made from English language to local Tigrigna language and back to English language by different experts who are familiar on the field of area and blind to the original version of the questionnaire because of facilitate reliable responses to underline questions and keep the original meaning of the instruments. Structured Questionnaires which contain open and closed ended questions and used to collect the data with face-to-face interview.

\subsection{Data Collection Procedure}

The data were collected for twenty-one days study in kebele02, Quiha Woreda, Mekelle Zone, Tigray, Ethiopia. It was collected through face to face interview of selected participants at their houses or on working places by using Tigrigna version instrument according to the information taken from communities. One trained Diploma nurse and three health extension supervisors were involved in data collection and was supervised by one bachelor degree nurse. For both data collectors and supervisors one day training was given on data collection instrument, interview technique and importance of taking informed consent before data collection starts. Each day data was checked for completeness and consistency.

\subsection{Data Processing and Analysis}

After coding and cleaning, data was entered and analyzed by SPSS window version 16 . The analysis part was consisted of descriptive statistics using tables and graphs to describe the study population. And p-value less than 0.05 and $95 \%$ confidence interval was used to show the association between the dependent and independent variables. Before data analysis, data review was done during data entry however, in questionnaires with minor loss of information, replacement of missing values ( for numerical variables) was done before analysis the collected data was filled of stored in the prepared format then summarized and distributed to tables, graphs and charts. After collection all the data analysis was made by manually using scientific calculator by the principal investigators and also analyzed by using appropriate statically methods like chi square and comparisons of results with similar studies was attempted.

\subsection{Operational Definitions}

Those parents who have acquire the ability to read and write the skill trough informal education.

Abstinence - To be reserved from sexual relation ship

Adolescence- A period of life age 10-19 year according who

Antenatal coverage- which pregnant women attended at least once during the current pregnancy and previous (past) history by a health professional for reasons related to pregnancy.

Condom- is a plastic rubber that can be used sexual intercourse to prevent STI and HIV/AIDS and assess as a method of family planning

Contraceptive acceptors rate - proportion of women reproductive age (15-49) years who are accepting a modern contraceptive method new and repeat acceptors.

Delivery attended -In this study used to know about service given for pregnant women during labor and management of normal delivery and defection of complication management of risk cases in labor and complicated case.

Effectiveness- Concerned with achievement of the program objectives

Knowledgeable - Those who have Knowledge about safe sexual behavior.

Less than $12^{\text {th }}$ grade - Those parents who have acquired skill through formal education.

Partner -Sexual partner who had been together for less than 12 months were not married and had never together lived for and did not make any payment for sex

Perception - Special arrangement for future outlook towards safe sexual behavior and practices.

Reproductive health - is also of complete physical mental 
and social well being and not merely the absence of disease or infinity in all matters related to the reproductive system and its function and process.

Self-esteem- one's good opinion of own worth.

Utilization - The state of having been made use of the rate of utilization.

\subsection{Data Quality Control}

To ensure the quality of data ,first the questionnaire was pretested the pretested was conducted in 5\% of the participants at randomly selected Kushet in Keble 02,Quhia Woreda, Mekelle Zone, Tigray Training was given for the data collectors and supervisors before the actual data collection, questionnaires were reviewed and checked for completeness, accuracy and clarity by the supervisors and principal investigators.

\subsection{Ethical Consideration}

Ethical clearance letter was obtained from Sheba University College to Quiha health center. Having the ethical clearance, the objective of the study was discussed with the community and staff members and health package workers for their cooperation for the CBTP phase final activities. Informed consent was also obtained from the community members. Besides, the Objective of the study briefed to the community members before they fill in the questionnaires. They were also informed that their participation is fully voluntary and as such they would have the right to leave the questionnaire. If they were comfortable. The principal investigators were also making a daily cross-check for appropriate data handling, not to expose information. After data collection, the questionnaires were kept confidentially. The finding of this study will be disseminated to Quiha health center. It will also be disseminated to Quiha town Administration to Sheba University College, to the advisor and to other governmental and non-governmental organization that are involved in related activities. Findings will also be presented in relevant seminal and work shop.

\subsection{Limitation of the Study}

- Community fatigue due to previous done student.

- Closure of some house during the study

- Refusal of respondents to tell their annual income due to fear of taxation

- Shortage of trained man power especially on the community set up or activities related to health care

- Due to lack of awareness or shortage of Knowledge about health some of community has a negative feeling on health services.

- Lack of stationary such as pen

\section{Result}

Among the 360 respondents the females were $252(70 \%)$ and males were $108(30 \%)$ by sex. Above $63(17.5 \%)$ male and $108(30 \%)$ female were $31-45$ by age in between. Among the majority respondents $75(20.8 \%)$ male were married and $110(30 \%)$ female were divorced by marital status. Out of farmers merchants office workers and daily workers the remaining $60(16.6 \%)$ male and $128(35.5 \%)$ female were categorized under others by occupation. About the 360 respondents the majority which is $62(17.2 \%)$ male and 126 (35\%) female live in rental house and the least $4(1.1 \%)$ female like in NGOS by ownership of house. About 55 $(15.1 \%)$ male's salary was $=1200$ and $100(27.7 \%)$ female's salary was $<200$ birr by monthly income. The study reveals that all most all respondents $108(30 \%)$ male and $248(68.8)$ female were Tigray by Ethnicity. About 50 (13.8\%) male were $12 \mathrm{t}$ and $72(20 \%)$ female were Illiterate by educational status. Among the 360 respondents $122(13.2 \%)$ male and 129 (14\%) female were between 19-30yrs old by number of family members. The study reheated that $176(48.8 \%)$ male and $180(50 \%)$ female were attending school by the number of children attending school. The study reheated that all the 360 respondents $108(30 \%)$ male and $252(70 \%)$ female were on the orthodox by religion. Among merchant government workers the remaining 65(18\%) male and 119 933\%) female were categorized under by occupation of the spouse. (Table 1)

Table 1. distribution of social-demographic characteristics of communities in Keble 02, Quiha Woreda, Mekelle zone, Tigray, Ethiopia, 2010.

\begin{tabular}{|c|c|c|c|c|c|c|c|c|}
\hline & Characteristics & & Male & & Femal & & Total & \\
\hline \multirow[t]{4}{*}{1} & Sex & & No & $\%$ & No & $\%$ & No & $\%$ \\
\hline & & & 108 & 30 & 252 & 70 & 360 & $100 \%$ \\
\hline & & Up 6 years old & 2 & 0.42 & 25 & 5.25 & 27 & 5.67 \\
\hline & & From 6_12 years old & 8 & 1.68 & 38 & 7.89 & 46 & 9.57 \\
\hline \multirow[t]{6}{*}{2} & Age & 13_18 years old & 17 & 3.57 & 40 & 8.4 & 57 & 11.97 \\
\hline & & 19-30. years old & 18 & 4 & 42 & 8.82 & 60 & 12.82 \\
\hline & & $31-45$ & 63 & 13.23 & 108 & 22.68 & 171 & 35.92 \\
\hline & & Total & 108 & 30 & 252 & 70 & 360 & 100 \\
\hline & & Single & 4 & 1.11 & 10 & 2.77 & 14 & 3.88 \\
\hline & & Married & 75 & 20.83 & 64 & 17.77 & 139 & 38.61 \\
\hline \multirow[t]{3}{*}{3} & Marital State & Widowed & 4 & 1.11 & 50 & 13.88 & 54 & 15 \\
\hline & & Separated & 4 & 1.11 & 18 & 5 & 22 & 6.11 \\
\hline & & Divorce & 21 & 5.83 & 110 & 30 & 131 & 36.38 \\
\hline
\end{tabular}




\begin{tabular}{|c|c|c|c|c|c|c|c|c|}
\hline & Characteristics & & Male & & Femal & & Total & \\
\hline \multirow{7}{*}{4} & \multirow{7}{*}{ Occupation } & Total & & 30 & 252 & 70 & 360 & 100 \\
\hline & & Farmer & - & - & - & - & - & - \\
\hline & & Merchant & 20 & 5.55 & 108 & 30 & 128 & 35.55 \\
\hline & & Office Worker & 28 & 7.77 & 16 & 4.44 & 44 & 12.22 \\
\hline & & Daily Worker & - & - & - & - & - & \\
\hline & & Others & 60 & 16.66 & 128 & 35.55 & 188 & 52.22 \\
\hline & & Total & 108 & 30 & 252 & 70 & 360 & 100 \\
\hline \multirow{6}{*}{5} & \multirow{6}{*}{ Monthly income } & $<=200$ Birr & 21 & 5.83 & 100 & 27.77 & 121 & 58.58 \\
\hline & & $200-400$ & 14 & 3.88 & 79 & 21.94 & 93 & 25.83 \\
\hline & & $401-600$ & 18 & 5 & 34 & 9.44 & 52 & 14.44 \\
\hline & & $601-1200$ & - & - & - & - & & \\
\hline & & $>=1200$ & 55 & 15.27 & 39 & 10.83 & 94 & 26.11 \\
\hline & & Total & 108 & 30 & 252 & 70 & 360 & 100 \\
\hline \multirow{4}{*}{6} & \multirow{4}{*}{$\begin{array}{l}\text { Owner ship of } \\
\text { house }\end{array}$} & Private & 46 & 12.77 & 122 & 33.88 & 168 & 46.66 \\
\hline & & NGOs & & & 4 & 1.11 & 4 & 1.11 \\
\hline & & Rental/Keble & 62 & 17.22 & 126 & 35 & 188 & 52.22 \\
\hline & & Total & 108 & 30 & 252 & 70 & 360 & 100 \\
\hline \multirow{5}{*}{7} & \multirow{5}{*}{ Ethnicity } & Oromo & - & & - & & - & \\
\hline & & Amhara & - & 4 & & 1.11 & 4 & 1.11 \\
\hline & & Gurage & - & & - & & - & \\
\hline & & Tigray & 108 & 248 & & 68.88 & 356 & 98.88 \\
\hline & & Total & 108 & 252 & & 70 & 360 & 100 \\
\hline \multirow{6}{*}{8} & \multirow{6}{*}{ Educational Status } & Illiterate & 10 & 2.78 & 72 & 0.5 & 82 & 22.77 \\
\hline & & Read and write & 14 & 3.89 & 18 & 5 & 32 & 8.99 \\
\hline & & Grade 1-6 & 10 & 2.78 & 82 & 22.77 & 92 & 25.55 \\
\hline & & Grade7-11 & 24 & 6.67 & 54 & 15 & 78 & 21.66 \\
\hline & & $12+$ & 50 & 13.89 & 26 & 7.22 & 76 & 21.11 \\
\hline & & Total & 108 & 30 & 252 & 70 & 360 & 100 \\
\hline \multirow{8}{*}{9} & \multirow{8}{*}{$\begin{array}{l}\text { Number of Family } \\
\text { member }\end{array}$} & Up to six years old & 36 & 3.10 & 43 & 4.67 & 79 & 21.94 \\
\hline & & 6-12 years old & 108 & 11.73 & 108 & 11.73 & 216 & 60 \\
\hline & & 13-18 years old & 90 & 9.78 & 111 & 12.06 & 201 & 55.83 \\
\hline & & $19-30$ years old & 122 & 13.26 & 129 & 14.02 & 251 & 69.7 \\
\hline & & $31-45>>$ & 43 & 4.67 & 64 & 6.95 & 107 & 29.72 \\
\hline & & $46-69>>$ & 10 & 1.08 & 21 & 2.28 & 31 & 8.61 \\
\hline & & Above 60years old & 10 & 1.08 & 25 & 2.71 & 35 & 9.72 \\
\hline & & Total & 419 & 45 & 494 & 53.69 & 920 & 100 \\
\hline \multirow{4}{*}{10} & \multirow{4}{*}{$\begin{array}{l}\text { Number of } \\
\text { children attending } \\
\text { School }\end{array}$} & 1 & 176 & 42.7 & 180 & 43.68 & 356 & 98.88 \\
\hline & & 2 & 21 & 5.09 & 10 & 2.42 & 31 & 8.61 \\
\hline & & $>=3$ & 4 & 0.97 & 21 & 5.09 & 25 & 6.94 \\
\hline & & Total & 201 & 48.78 & 211 & 51.21 & 412 & 114.44 \\
\hline \multirow{6}{*}{11} & \multirow{6}{*}{ Religion } & Orthodox & 108 & 30 & 252 & 70 & 360 & 100 \\
\hline & & Muslim & - & - & - & & - & \\
\hline & & Catholic & - & - & - & & - & \\
\hline & & Protestant & - & - & - & & - & \\
\hline & & Others & - & - & - & & - & \\
\hline & & Total & 108 & 30 & 252 & 70 & 360 & 100 \\
\hline \multirow{5}{*}{12} & \multirow{5}{*}{$\begin{array}{l}\text { Occupation of the } \\
\text { spouse }\end{array}$} & Farmer & - & & - & & & \\
\hline & & Merchant & 7 & 1.94 & 96 & 26.66 & 103 & 28.61 \\
\hline & & Government Worker & 36 & 10 & 36 & 10 & 72 & 20 \\
\hline & & Others & 65 & 18.05 & 119 & 33.05 & 184 & 51.11 \\
\hline & & Total & 108 & 30 & 252 & 70 & 360 & 100 \\
\hline
\end{tabular}


The Figure shows that most of age at first marriage were $184(51 \%)$ in b/n 15-19 years old. of which the least were
$7(2 \%)$ in b/n 30-34 years old but about $97(27 \%)$ were at age $<15$ yrs old. (figure1)

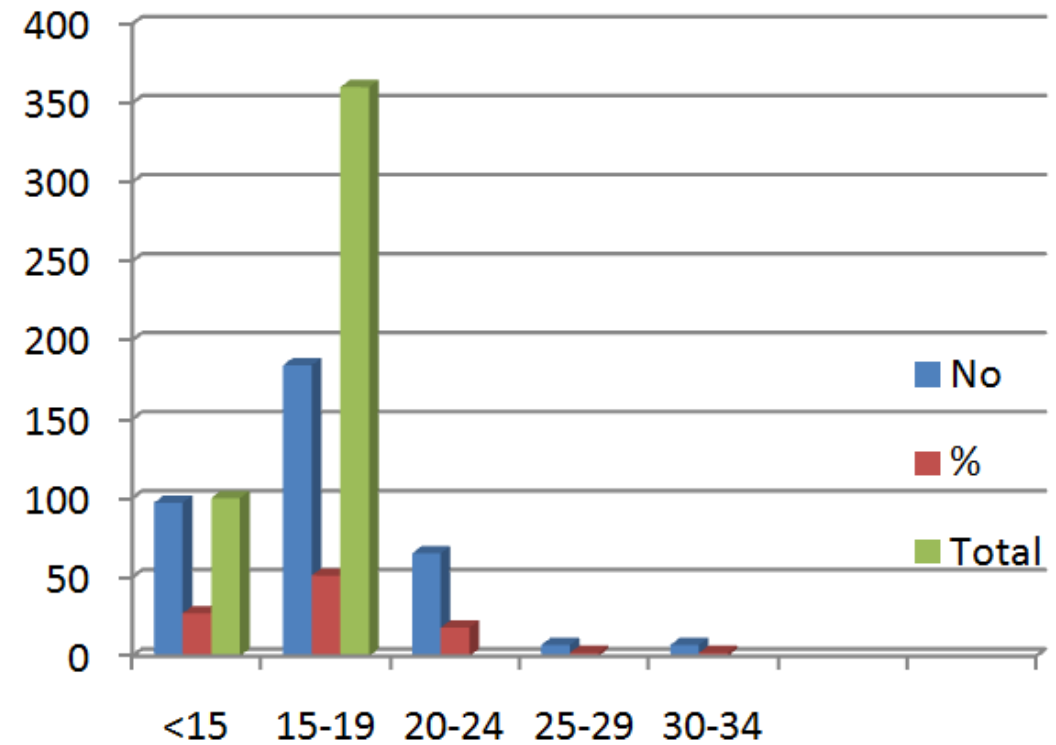

Figure 1. The number of respondent who were married for the first time by age in Keble 02-Quiha Woreda, Mekelle zone, Tigray, Ethiopia, 2010.

The Figure indicates that out the 360 respondents 223(62\%) were experiencing first pregnancy at the age of 15-19 years old .while $22(6 \%)$ experienced at the age of $<15$ years old.(Figure 2)

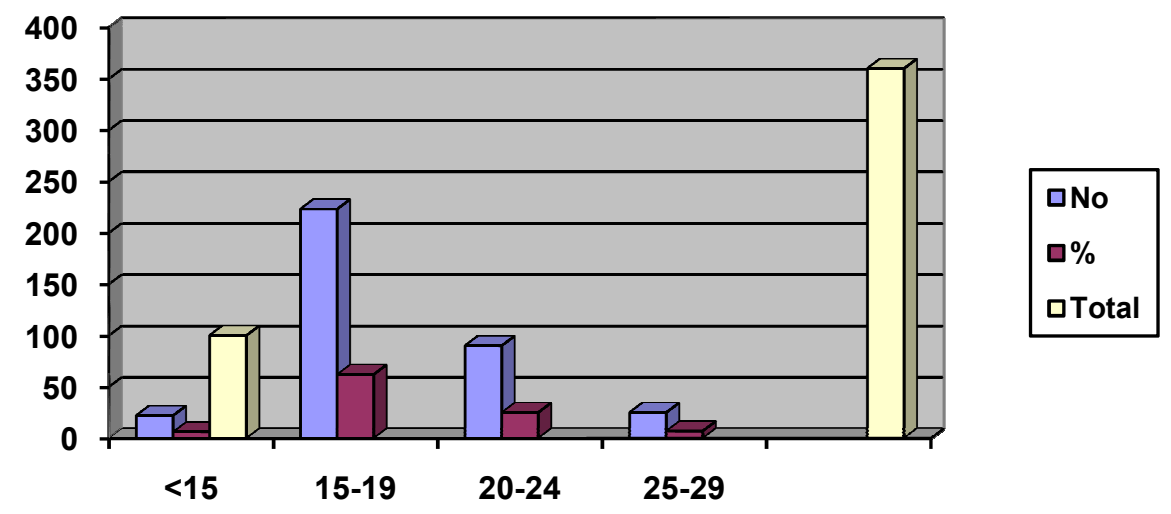

Figure 2. Percentage Distribution of women's who had their first pregnancy at age interval in Keble 02 Quiha Woreda, Mekelle zone, Tigray, Ethiopia, 2010.

This indicates that among the 360 respondents $79(22 \%)$ had 5-6 pregnancy while $32(9 \%)$ had no pregnancy at all. (Table2)

Table 2. Total Number of Pregnancy in Quiha Woreda, Keble 02, Mekelle zone, Tigray, Ethiopia,2010.

\begin{tabular}{llll}
\hline No & Total Number of Pregnancy & No & \% \\
\hline 1 & 1 & 61 & 17 \\
2 & 2 & 49 & 13 \\
3 & $3-4$ & 72 & 20 \\
4 & $5-6$ & 79 & 22 \\
5 & $>=6$ & 67 & 19 \\
6 & None & 32 & 9 \\
& Total & 360 & 100 \\
\hline
\end{tabular}

The study shows that out of the 360 respondent $198(55 \%)$ were not prohibited food during pregnancy which 162 (45\%) were prohibited food during pregnancy (Table-3)

Table 3. The Number of pregnant mothers was prohibited from food during pregnancy in Keble 02, Quiha Woreda, Mekelle zone, Tigray, Ethiopia, 2010.

\begin{tabular}{llll}
\hline No & Food Prohibited During Pregnancy & NO & \% \\
\hline 1 & Yes & 162 & 45 \\
2 & No & 198 & 55 \\
& Total & 360 & 100 \\
\hline
\end{tabular}

The study result shows that majority of pregnancy women who abused by their pregnancy in the community for the 
majority 201 (56\%), for psychological and the least number $158(44 \%)$ were physically (Figure 3)
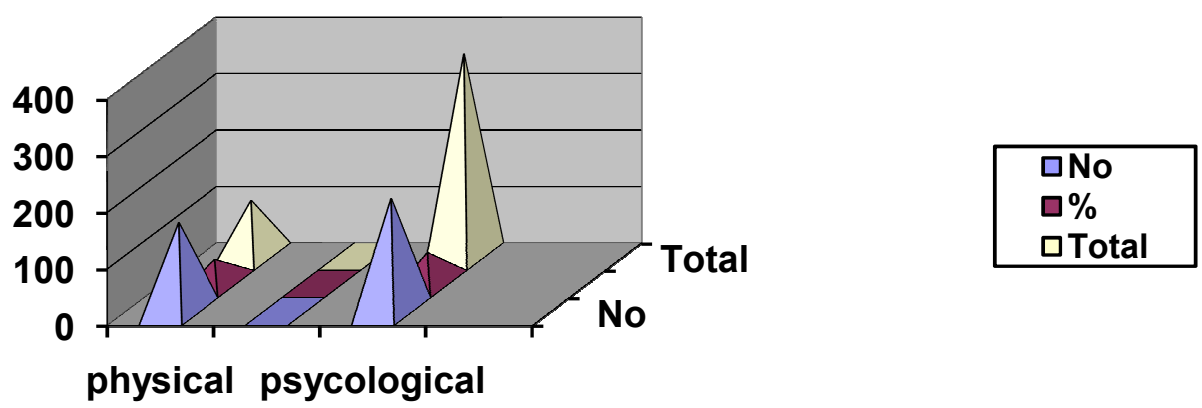

Figure 3. The Number of pregnant women who abused by their pregnancy in the communities of Keble 02 Quiha Woreda, Mekelle Zone, Tigray, Ethiopia, 2010 .

Table 4. Number of Children died and alive in the community of Keble 02, Quiha Woreda, Mekelle Zone, Tigray, Ethiopia, 2010.

\begin{tabular}{llll}
\hline Total No of children alive & & No & \% \\
\hline & 1 & 57 & $30 \ldots 7$ \\
& 2 & 54 & $28.8 \%$ \\
& $3-4$ & 68 & $36.5 \%$ \\
& $>=5$ & 7 & $3.8 \%$ \\
& Total & 186 & $100 \%$ \\
Died $<1$ year & & 50 & 35.8 \\
$1-4$ year & & 43 & 30.7 \\
$>=5$ & & 46 & 33.3 \\
Total & & 139 & 100 \\
& & No & $\%$ \\
No of Abortion & 1 & 21 & 66.6 \\
& 2 & 4 & 11.1 \\
& $>=4$ & 7 & 22.2 \\
& Total & 35 & 100 \\
No of Still birth & & No & $\%$ \\
& 1 & 28 & 72.7 \\
& 2 & 7 & 18.18 \\
& $>-3$ & 4 & 9.1 \\
& Total & 39 & 100 \\
\hline
\end{tabular}

The study result indicates that in the study area age $<1 \mathrm{yr}$ the majority of $68(36.5 \%)$ were $3-4 y r s$ of age number of children alive. The majority of deaths from children died in the community occurred in the age group $<1 \mathrm{yr}$ which accounts for the majority 50(35.8\%) and the least 1-4 years accounts for $43(30.7 \%)$ and $>5$ years accounts for $46(33.3 \%)$. About number of abortion indicates that the number of abortion for the majority of $21(66.6 \%)$ were one times and the least number $>$ three times $67(22.2 \%)$ the rest $4(11.1 \%)$ are aborted 2 times. And the study result of Still birth the majority 28 (72.7) were one times and the least number $>3$ are $(9.1 \%)$ the least $7(18.18 \%)$ are 2 times (Table 4).

The study result indicated that the majority of the community that delivers at home was $176(49 \%)$ and the least number $34(9 \%)$ where delved other places of their last child. The remaining 39(11\%), 111 (31\%) are delivering in health station, 4 hospitals respectively.

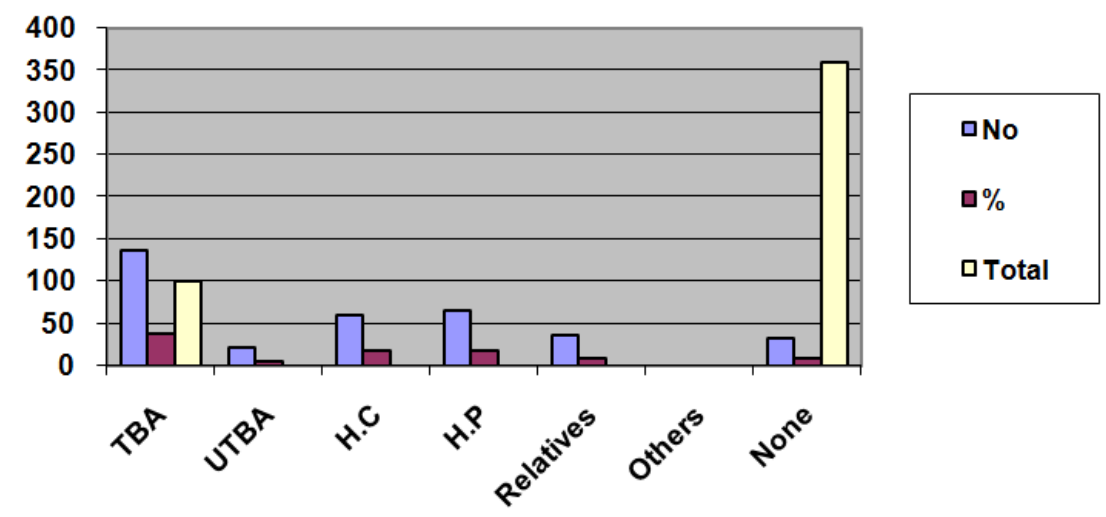

Figure 4. Birth attendant who was performed the delivery in Keble 02 Quiha Town, Mekelle Zone, 2010.

Table 5. Number of respondent who seek health facility during pregnancy in Keble 02, Quiha town, Mekelle Zone, Tigray, Ethiopia, 2010.

\begin{tabular}{llll}
\hline No & Health Facility during Pregnancy & NO & $\%$ \\
1 & Yes & 252 & 70 \\
2 & No & 76 & 21 \\
3 & None & 32 & 9 \\
& Total & 360 & 100 \\
\hline
\end{tabular}

The study revealed that out of the 360 respondent $252(70 \%)$ seek health facility during pregnancy while $32(9 \%)$ didn't seek health facility during pregnancy (Table5).

The study results indicates that the majority of women start to breast feed their babies were $288(80 \%)$ and women who breast feed their babies $>6$ hrs after birth acconts $32(9 \%)$ the remaining $40(11 \%)$ start breast feeding at 


\section{1-2 hrs after birth.(Table6)}

Table 6. The point of time at $w / c$ breast feeding was started among reproductive age women's of Keble 02, Quiha town, Mekelle zone, Tigray, Ethiopia, 2010.

\begin{tabular}{llll}
\hline No & Starting breast feeding birth & N0 & \% \\
\hline 1 & Immediately after birth & 288 & 80 \\
2 & $1-2$ hrs after birth & 40 & 11 \\
3 & $3-5$ after birth & - & - \\
4 & 6 after birth & 32 & 9 \\
& Total & 360 & 100 \\
\hline
\end{tabular}

The study result shows that starting of additional food for last body majority $144(40 \%)$ were $4-6$ month \& the least No to start their additional food their body were 7-11month $14(4 \%)$ started. The remaining are 1-3 month, 18 (5\%) \&> year $46(13 \%)$ started. (Table 7)

Table 7. The age of staring additional food for the last baby at Keble 02, Quiha Woreda, Mekelle ZoneTigray,Ethiopia,2010.

\begin{tabular}{llll}
\hline No & Age of Starting additional food for the last baby & No & \% \\
\hline 1 & At birth & - & - \\
2 & $1-3$ month & 18 & 5 \\
3 & $4-6$ month & 144 & 40 \\
4 & Month 7-11 & 14 & 4 \\
5 & 1year & 46 & 13 \\
& Total & 222 & 62 \\
\hline
\end{tabular}

\section{Discussion}

In our study of Scio- demographic characteristics revealed that the majority $63(17.5 \%)$ of male and $108(30 \%)$ of female respondent by age lie between $31-45,75(20.83)$ of male married and 110(30\%) female divorce by marital status .Out of farmer, Merchant, office worker daily and worker the remaining $60(16.66 \%)$ of male were categorized under others $108(30 \%)$ of females were merchants by occupation.108(30\%)male,248(66.8\%) female were Tigrigna by Ethnicity, $108(30 \%)$ of male, $252(70 \%)$ of female were orthodox by religion,50 (13.89\%) of male $12,72(0.5 \%)$ of female were illiterate by educational status.55(15.27\%) of male $\geq 1200,100(27.7 \%$ ) of female, monthly income lies in $<200$ birr per month. As the study compared with study done in Jimma in 2007 revealed that majority 59(23.6\%) of the respondents by age lie between 25-29 186(74.4\%) Muslim by religion, $189(79.2 \%)$ Oromia by ethnicity, $219(87.6 \%)$ Married, $150(60 \%)$ illiterate by educational status, $103(41.2 \%)$ farmer by occupation and $40.7 \%(102)$ of their monthly income lies between 106-400 birr per the difference is almost on some characteristics (18). The study result a married women age group between age intervals of 15-19 is $51 \%$ when this study was compared with study done by DHS, which accounts $18 \%$. This difference can be due to the difference in sample size (10). The study result on age of women at their first pregnancy revealed that the majority of the women in the community had their first pregnancy in the age group 15-19 accounting for $62 \%$ and $25 \%$ were at age group between 20-24 $(18,19)$. The study revealed that among the pregnant women of Quiha community the pregnant outcome of live birth accounts for $36.5 \%$ age 3-4 where are skill birth and abortion accounting for $72.7 \%$ and $66.6 \%$ respectively and number of died account for a cross sectional survey of sample data was collected in 1996 E.C neonatal death $21 / 1000$, and still death $6 / 1000$ - this can due to the difference in sample size $(20,21,22)$. The study result on place of delivery shows as most of the women in the community delivery account $49 \%$ of all the attendants of those delivers in the community majority are TBA and Neighbor accounting for $38 \%$ and $19 \%$ respectively the percent of births attended by health personnel is $18 \%$ relative to the study conducted by $\mathrm{MOH}$ on health and health related indicators $16.4 \%$ are attended by skilled health personnel $7.3 \%$ are attended by TBA our study result is greater this result can be because of lack of awareness in the community on appropriate place of delivery and birth attendant and their awareness towards health facility seeking for their regular cheek up during their pregnancy accounts for $70 \%$ and $21 \%$ seec health facility while they are sick $9 \%$ seek health facility for other purpose when compared to the study done in Jimma University in2007 regular cheek up of pregnant mother which account $69 \%$ and $21 \%$ seek health facility while they are sick, $10 \%$ seek health facility doe other purpose. The difference is almost comparable (10). The study also indicate that most of the among the study population both their babies immediately offer birth which account $70 \%$ when we compare to the study done in Jimma in 2007.baths their babies immediately which account for $82.4 \%$ the difference indicate that the previous result is higher because of higher awareness on health education.(10)The study shows that the point at which breast feeding is started shows the majority of reproductive age women starts breast feeding immediately after birth which account for 288(80\%) and $>6 \mathrm{hrs}$ after birth which account for 32(9\%). When compared the result with the study conducted in Jimma University breast feeding started immediately after birth which account $198(79.2 \%$ and $>24 \mathrm{hrs}$ offer birth which account $26(10.4 \%)$ the difference is comparable (18)The study also indicate that out of the 360 respondent $198(55 \%)$ were not prohibited food during pregnancy while 162\%) where prohibited food during pregnancy. As compared with the previous study done in Jimma the majority 70(61.94\%) of the pregnant mother's was prohibited from maize and maize products the difference could be the different culture in the countries $(18,19,20,21,22)$. As the study revealed that majority of respondents were used both feeding for their babies were not used which account 67.2 as compared with the study done at Jimma butter Keble in 2007 November of respondent used both feeding $79.6 \%$ the difference in the community are bused during pregnancy psychological and physical which account $56 \%$ and $44 \%$ respectively. When the study compare with the study done in Jimma mothers abused by their partner during pregnancy of which account $42.85 \%$ are abused physically the difference is almost compared. The study result on harmful traditional practice revealed that the main harmful traditional practice which exercises among the community are Uvula cutting which accounts for $54.8 \%$ 
female circumcision $8.65 \%$,and extraction of milk tooth $34.6 \%$ As the result of the study compared with the study done in Jimma in 2007, respondents who exercised Uvula cutting accounts 18.645 and tooth extraction $11.47 \%$. It indicates that there is high practice in our study this difference is due to lack of information and lack of health education.

\section{Conclusion}

The majority of respondents were married at age interval of 15-19 this indicates that there is early marriage in the community. The majority of respondents were pregnant at age interval of 15-19 years old and some of the community exercise $<15$ years old then we have to give health education for them about the harmfulness of the early marriage. The majority of respondents were delivered in their home. Then this shows what lack of awareness and lack of health institution in their environment and there was dominancy of UTBA.

\section{Author's Contributions}

AAG and WGK have made substantial contributions to beginning and design, collection of data, analysis and interpretation of data and in drafting the manuscripts and correcting the comment given by the Advisors. All Authors involved in revising the research paper and the manuscript critically for important intellectual context and approval of the final version to be published and participated in its design and coordination. He participated in the approval and funding process, participated in the design of the study participated in its design and coordination.

\section{Acknowledgements}

We are thankful to all our department technical staffs for their excellent technical support. We are grateful to all the participants for their cooperation and Sheba University College for financial support only for completed this CBTP program.

\section{References}

[1] Hall KS, Moreau C, Trussell J (2012). "Determinants of and Disparities In Reproductive Health Service Use Among Adolescent And Young Adult Women In The United States, 2002-2008". American Journal of Public Health 102 (2): 359367 - via Academic Search Premier.

[2] World Health Organization (2008). Reproductive health. Retrieved http://www.who.int/topics/reproductive health/en/on 2008-0819.

[3] Best Start Resource Centre and Motherisk (2008). Screening for alcohol use in pregnancy, physician's desk reference. Toronto (ON): 2008. Retrieved Jun 20, 2009. Available from: www.beststart.org/resources/alc_reduction/index.html
[4] Synthesis on parenting skills. In: Tremblay RE, deV Peters R, Boivin M, Barr RG, editors. The Encyclopedia on Early Childhood Development. Published online Mar 262007. [Updated Nov 26, 2008]. Retrieved Jun 20, 2009.

[5] Best Start Resource Centre. Preconception health: public health initiatives in Ontario. Toronto (ON): 2009. Retrieved Jun 20, 2009. Available from: www. Best start. Org/resources/ preconception /index.html

[6] Nicole Cheetham, N (2002). Community participation: What is it?.Transitions: Community Participation 14 (3): http://www.advocatesforyouth.org/component/content/683?tas $\mathrm{k}=$ view

[7] Haub C and Sharma OP, India's population reality: reconciling change and tradition, Population Bulletin, 2006, Vol. 61, No. 3 .

[8] IIPS, 2005-2006 National Family Health Survey (NFHS-3): National Fact Sheet, India (Provisional Data), Mumbai: IIPS, 2007.

[9] Daniel, EE.,Rekha Masilamani ,R., Rahman,M (2008). The Effect of Community-Based Reproductive Health Communication Interventions on Contraceptive Use Among Young Married Couples in Bihar, India. International Family Planning Perspectives 34(4): 189-197

[10] Live births by age of mother and sex of child, general and agespecific fertility rates: latest available year, 2000-2009 United Nations Statistics Division - Demographic and Social Statistics

[11] De Francisco, A., Dixon-Mueller, R., D'Arcangues, C (2008).Research Issues in Sexual and Reproductive Health for Low- and Middle-Income Countries (Geneva: Global Forum for Health Research and World Health Organization, 2007).

[12] Mabry, R., Al-Riyami, A., Morsi, M (2007). "The Prevalence of and Risk Factors for Reproductive Morbidities among Women in Oman," Studies in Family Planning38, no.2 (2007): $121-28$

[13] Kabakian-Khasholian, $\mathrm{T}$ et al(2007). "The Policy Environment Surrounding Caesarean Section in Lebanon, "Health Policy 83(1): 37-49.

[14] Family Planning Manual for health workers (MOH, FGAE) 1996.

[15] Health and health related Indicators, FMOH 1998(2005/06 GC)

[16] Tadesse, K., Haile, A., Tezera, M., Tewele, A (2014).Access to Institutional Delivery of Mothers in Adigrat Town, Northern Ethiopia. American Journal of Nursing Science. Vol. 3, No. 5, 2014, pp. 87-90. doi: 10.11648/j.ajns.20140305.15

[17] Written document done in Jimma University CBTP programmed in 2007.

[18] Nursing community Based Training Program house hold survey in Sheba University college July, 2009.GC

[19] Curriculum development of Zonal Mekelle

[20] Assessment of Knowledge, attitude and Practice on family planning among reproductive age (15-49) group females in WoredaSaisietsaedaemba, Frewyni town, Easter Tigray Research conducted by Mekelle University health officers on November 2007 
[21] Maritine Collumbiaen, BrajDasoona, M-R Campbell, India 2001, why are condoms used, and how many are needed? Estimates from India (Orissa).

[22] Malalu,PK.,Alfred,K.,Too,R.,Chirchir,A(2014). Determinants of Use of Modern Family Planning Methods: A Case of Baringo North District, Kenya. Science Journal of Public Health. Vol. 2, No. 5, 2014, pp. 424-430. doi: 10.11648/j.sjph.20140205.18

[23] Negashi, Y., Gebre., Benti, D Gambella 2000, Community based study on KAP on HIV/AIDS in Gambella town, western Ethiopia. 